\title{
Diversified 及-2-adrenergic Receptor Expression and Action in Melanoma Cells
}

\author{
MARCELINA ELŻBIETA JANIK ${ }^{1}$, DOMINIKA SZLEZZAK ${ }^{1}$, MAGDALENA SURMAN ${ }^{1}$, \\ ANIELA GOŁAS ${ }^{2}$, ANNA LITYŃSKA ${ }^{1}$ and MAŁGORZATA PRZYBYŁO ${ }^{1}$ \\ Departments of ${ }^{1}$ Glycoconjugate Biochemistry and ${ }^{2}$ Genetics and Evolution, \\ Jagiellonian University in Krakow, Kraków, Poland
}

\begin{abstract}
Background/Aim: Growing evidence links stress hormones with development and progression of various cancer types. The aim of this study was to assess susceptibility of cutaneous and uveal melanoma cells to adrenaline $(A D)$. Materials and Methods: The expression of $\beta$-2-adrenergic receptor in primary cutaneous (FM-55-P), primary uveal (92-1, Mel202) and metastatic cutaneous (A375) melanoma cells was estimated at $m R N A$, protein and cell surface levels. The impact of $A D$ on cell proliferation and migration was also studied. Results: The expression of $\beta$-2-adrenergic receptor was cell line-dependent. Adrenaline treatment caused a slight stimulation of melanoma cell proliferation and activation of matrix metalloproteinases. Adrenaline-treated uveal melanoma cells showed an increased migration rate, whereas, in cutaneous melanoma cells, no changes or even lower migration speed were observed. Conclusion: Melanoma cell susceptibility to AD varies depending on origin and progression stage. Metastatic cutaneous melanoma cells were found to be less responsive to $A D$ than primary cutaneous and uveal melanoma cells.
\end{abstract}

The high mortality rate associated with melanoma is attributed to the high invasiveness of tumour cells that becomes apparent very early during disease progression (1). Among the classical risk factors, such as ultraviolet (UV) exposure, sunburn, fair skin type, gender or age (2), psychological stress is also considered to be an important factor in melanoma development $(3,4)$. There is growing evidence showing that the chronic stress and depression

Correspondence to: Marcelina E. Janik, Ph.D., Department of Glycoconjugate Biochemistry, Institute of Zoology and Biomedical Research, Jagiellonian University in Krakow, 9 Gronostajowa St., 30-387 Kraków, Poland. Tel: +48 126646467, Fax: +48 126645101, e-mail: marcelina.janik@uj.edu.pl

Key Words: Beta-2-adrenergic receptor, adrenaline, uveal melanoma, cutaneous melanoma, matrix metalloproteinases. experienced by oncological patients accelerate the course of disease progression (5). Stress-related immunosuppression is suggested to be the main cause of an increased tumour growth and faster spread of metastatic cancer cells (6), including melanoma (7). Nevertheless, it has been recently accepted that stress effectors, such as chemokines and neurotransmitters (adrenaline (AD)) can also directly affect cancer cells and, thereby, influence disease/tumour progression $(8,9)$. Cancer cell dissemination is a multistep process (10) during which the cells are not only under the influence of local microenvironment, but also tightly regulated by intracellular signalling pathways. Many cancer cells have been shown to express adrenergic receptors and to be sensitive to catecholamine stimulation (11). The involvement of $\beta$-adrenergic receptor (ADRB) signaling in cancer progression has been confirmed with the use of $\beta$ blockers. The antiproliferative and pro-apoptotic effects of propranolol, a non-selective $\beta$-blocker for ADR1B and ADR2B, have been observed in hemangioendotheliomas and angiosarcomas (12), gastric cancer (13), breast cancer (14) and neuroblastoma (15). In a melanoma mouse model, the biphasic effect of propranolol on tumour growth has been shown, suggesting that tumour growth is inhibited by vasoconstrictive doses of propranolol, while vasodilating doses do not exert such effect (16). Moreover, propranolol has been shown to significantly reduce melanoma cell migration (17). In a breast cancer mouse model, propranolol lowers cell migratory potential, thereby blocking distant metastasis formation (18). Furthermore, until now, only a few studies have examined the molecular effects of $\mathrm{AD}$ on melanoma cells $(17,19)$.

In the present study, we examined the effect of $\mathrm{AD}$ stimulation on four melanoma cell lines that differ in their origin: cutaneous (CM), i.e. A375 and FM-55-P (metastatic and primary, respectively), as well as uveal (UM), i.e. 92-1 and Mel202 (both primary). We examined the influence of AD stimulation on ADR2B receptor expression on melanoma cell surface, as well as its impact on cell proliferation and migration. The ADR2B, which is the potent 
AD receptor (20), is known to be widely expressed in tissues and its extensive expression has been reported in cancer cells (21), including melanoma (17). We also investigated the activity of matrix metalloproteinases (MMPs) MMP-2 and MMP-9 reflecting the invasive ability of tumour cells.

\section{Materials and Methods}

Chemicals. AD and gelatin type B from bovine skin were obtained from Sigma-Aldrich (St. Louis, MO, USA). Rabbit anti-beta-2adrenergic receptor (ADR2B) antibody was obtained from Abcam (Cambridge, UK). SplitKits were purchased from Seralab (West Sussex, UK). Goat anti-rabbit IgG, horseradish peroxidase (HRP)linked antibody was purchased from Cell Signaling Technology (Danvers, MA, USA). Western Bright Quantum HRP substrate was a product of Advansta (Menlo Park, CA, USA). High Pure RNA Isolation Kit and Transcriptor High Fidelity cDNA Synthesis Kit were purchased from Roche Diagnostics GmbH (Mannheim, Germany). Foetal bovine serum, RPMI-1640 Glutamax- $I^{\circledR}$, Alamar Blue, SYBR ${ }^{\circledR}$ Green Master Mix, normal rabbit IgG isotype control and secondary donkey anti-rabbit antibody conjugated with AlexaFluor488 were purchased from Life Technologies (Carlsbad, CA, USA). Specific primers for Real-Time polymerase chain reaction (PCR) were obtained from Oligo.pl (Warsaw, Poland). All remaining chemicals were of analytical grade, commercially available.

Cell culture and treatment. A375 cell line (malignant CM) was purchased from ATCC (Manassas, VA, USA). Primary CM FM-55-P cell line, primary UM 92-1 cells and Mel202 cell line were obtained from ESTDAB Melanoma Cell Bank (Tübingen, Germany). The cells were maintained in RPMI-1640 Glutamax-I ${ }^{\circledR}$ medium (GibcoBRL, Paisley, UK) supplemented with $10 \%$ (v/v) heat-inactivated foetal bovine serum and penicillin $(100 \mathrm{U} / \mathrm{ml}) / \mathrm{streptomycin}(100 \mu \mathrm{g} / \mathrm{ml})$ solution. The cells were grown in monolayers at $37^{\circ} \mathrm{C}$ in a humidified atmosphere containing $5 \% \mathrm{CO}_{2}$. All experiments were initiated in sub-confluent cultures. In some experiments, cells were treated with $\mathrm{AD}(0.1,1,10,100 \mu \mathrm{M})$ for $12-24 \mathrm{~h}$ prior to assays.

Cell viability assay. Confluent cells were detached, pelleted and resuspended in assay medium. Subsequently, cells were counted and seeded into 96 -well plates at the density of $1 \times 10^{4}$ cells $/ 100 \mu \mathrm{l}$. On the following day, medium was changed and cells were incubated with different doses of AD. After $12 \mathrm{~h}$ of incubation, $10 \%$ Alamar Blue was added to each well. The mixture was incubated for $3 \mathrm{~h}$ and, then, fluorescence intensity was measured at 560/595 nm.

Real-Time PCR. Total RNA was extracted from cell lysates and 1 $\mu \mathrm{g}$ of total RNA was reverse-transcribed. The Real-Time PCR reactions were performed for 40 cycles of denaturation (15 sec, $95^{\circ} \mathrm{C}$ ), annealing/elongation $\left(1 \mathrm{~min}, 60^{\circ} \mathrm{C}\right)$. Amplification of $G A P D H$ mRNA was used as an internal control of efficiency of the reaction. The oligonucleotide sequences for $A D R 1 B, A D R 2 B$ and $G A P D H$ were as follows: for $A D R 1 B, 5^{\prime}$ CCTCGTCCGTAGT CTCCTTC3' and 5'GCAGCTGCTGATCTTCTTCA3'; for ADR2B, 5'AGAGCCTGCTGACCAAGAAT3' and 5'TAGCAGTTGATGG CTTCCTG3'; for GAPDH, 5'CAGCCTCAAGATCATCAGCA3' and 5'GTCTTCTGGGTGGCAGTGAT3'. The reaction results were analysed with a use of StepOne Software v 2.0 software (Thermo Fisher Scientific, Waltham, MA, USA).
Flow cytometry. The expression of ADR2B in control and ADstimulated cells was assessed by flow cytometry. Briefly, the cells were grown to sub-confluence and, then, either treated or not for 24 $\mathrm{h}$ with different doses of AD. Subsequently, cells were harvested with the use of SplitKits and diluted to $1.5 \times 10^{6} / \mathrm{ml}$ of PBS. Then, the cells were stained with either $1 \mu \mathrm{l}$ of rabbit anti-human antibody against ADR2B $(1 \mathrm{mg} / \mathrm{ml})$ or $0.25 \mu \mathrm{l}$ of normal rabbit $\operatorname{IgG}$ (negative control) $(3 \mathrm{mg} / \mathrm{ml})$ for $45 \mathrm{~min}$ at $4{ }^{\circ} \mathrm{C}$. After washing, cells were stained with $0.5 \mu \mathrm{l}$ of donkey anti-rabbit Alexa488-conjugated antibody $(2 \mathrm{mg} / \mathrm{ml})$ for $45 \mathrm{~min}$ at $4^{\circ} \mathrm{C}$ and washed again. The fluorescence of stained cells was measured by a FACSCalibur flow cytometer (BD Biosciences, San Diego, CA, USA). Three independent experiments were carried out.

Wound-healing assay. Wound-healing assay was performed in 6well culture plates that were either covered or not with fibronectin (FN). Briefly, melanoma cells were grown to confluence and, then, the cell-coated surface was scraped with a pipette tip in a single stripe. Subsequently, the surface was washed twice with PBS, covered with complete medium and wounds were allowed to heal for $24 \mathrm{~h}$ at $37^{\circ} \mathrm{C}$ in a humidified atmosphere. In some experiments, wound healing was performed in complete culture medium containing AD. Migration of cells into wounded areas was evaluated with an inverted microscope and photographed in 10 separated fields using Zeiss AxioVision Rel.4.8 image analysis software (Carl Zeiss Microscopy GmbH, Jena, Germany). The average extent of wound closure was evaluated by multiple measurements of the wound immediately after scraping and after $24 \mathrm{~h}$. Three independent experiments were carried out and all data are given as percentage of migration compared to untreated (control) cells migrating on plastic surface.

Zymography. The serum-free culture media, conditioned by CM and $\mathrm{UM}$ cells either treated or not with $\mathrm{AD}$, were normalized for protein concentration, mixed with Laemmli sample buffer without reducing agents $(10 \mu \mathrm{g}$ of total protein per line) without boiling. Then, samples were separated on $10 \%$ sodium dodecyl sulfate (SDS)-polyacrylamide gels containing copolymerised gelatin at final concentration of $1 \%$. After separation, the gels were washed in a solution of $2.5 \%$ Triton $\mathrm{X}-100(2 \times 15 \mathrm{~min})$ to remove SDS and after that in water $(2 \times 5 \mathrm{~min})$. In the next step, the gels were incubated for $24 \mathrm{~h}$ at $37^{\circ} \mathrm{C}$ in $50 \mathrm{mM}$ Tris/ $\mathrm{HCl}, \mathrm{pH} 8$, containing $0.15 \mathrm{M} \mathrm{NaCl}, 5 \mathrm{mM} \mathrm{CaCl}{ }_{2}$ and $0.02 \%$ sodium azide. Then, the gels were stained in $0.1 \%$ Coomassie Brilliant Blue R250 in a solution of $50 \%$ methanol and $10 \%$ acetic acid and, finally, destained. The dried gels were photographed with the use of a ScionImage software (Scion Corp., Frederick, MD, USA). The semiquantitative analysis of obtained bands intensity was conducted with the use UVImap V.99 software (UVItec, Cambridge, UK).

Cell lysate preparation. Cell pellets were homogenized in extraction buffer $(50 \mathrm{mM}$ Tris/HCl, pH 7.4, containing $150 \mathrm{mM} \mathrm{NaCl}$ and protease inhibitor cocktail) by sonification (UP50H; Hielscher Ultrasonics $\mathrm{GmbH}$, Teltow, Germany), followed by extraction for $30 \mathrm{~min}$ on ice in the same buffer containing additionally $0.03 \%$ protamine sulphate and $1 \%$ Triton X-100. Finally, cell extracts were clarified by centrifugation at $18,000 \times g$ for $25 \mathrm{~min}$. Protein concentration was determined in the supernatants according to Peterson (22). 
SDS-polyacrylamide gel electrophoresis (PAGE) and Western blot. The cell lysates were separated by $8 \%$ SDS-PAGE under reducing condition according to Laemmli (23) followed by transfer to a polyvinylidene difluoride (PVDF) membrane for $1 \mathrm{~h}$ at a constant voltage of $100 \mathrm{~V}$ with cooling. The blots were blocked in $1 \% \mathrm{BSA}$ in TBS/Tween (0.02 M Tris-HCl, pH 7.6, containing $150 \mathrm{mM} \mathrm{NaCl}$ and $0.1 \%$ Tween 20 ). Afterwards, membranes were incubated for 1 $\mathrm{h}$ with specific anti-ADR2B antibody diluted in TBS/Tween/1\% BSA (1:1,000 working dilution). After triple wash with TBS/Tween, blots were incubated with HRP-coupled goat anti-rabbit Ig (1:4,000 working dilution in TBS/Tween with $1 \%$ BSA) for $1 \mathrm{~h}$. The proteins were localised with the use of substrate for HRP.

Statistical analysis. Results are expressed as mean \pm standard deviation. Statistical analysis was performed with the use of Duncan's new multiple range test or Student's $t$-test and $p$-values of less than 0.05 were considered statistically significant. All data are the results of at least three separate experiments.

\section{Results}

$A D R 2 B$ expression in melanoma cells after $A D$ stimulation. First, we assessed the expression of ADR1B (ADRB1) and ADR2B (ADRB2) genes in quantitative assay, using $G A P D H$ mRNA as an internal control. It was shown that the $A D R 1 B$ mRNA expression level (data not shown) was negligible in comparison to the values for $A D R 2 B$ mRNA (Figure 1). These results were consistent with previously published observations (17); therefore, further analysis refers entirely to ADR2B receptor expression and action. We found that 921 cells showed the highest level of $A D R 2 B$ mRNA expression among all analysed melanoma cell lines. Western Blot analysis confirmed the expression of ADR2B at the protein level in all analysed cell lines (Figure 1).

The flow cytometry results demonstrated that the density of the cell surface expression of ADR2B receptor differed among the melanoma cell lines. The highest receptor density, expressed by relative fluorescence intensity (RFI) value, was detected in Mel202 cells and the lowest in FM-55-P cells. Also, in the case of A375 cells, the reported RFI value was low, suggesting presence of a small amount of the ADR2B receptor on the cell surface. These observations corresponded to the results of mRNA expression analysis. Moreover, referring to the percentage of cells, only a small percentage of A375 cells was ADRB-positive. Contrary to the observation related to RFI value, Mel202 cell line had the smallest population of ADR2Bpositive cells, whereas the FM-55-P cell line the largest (Figure $2 \mathrm{~A}$ and $\mathrm{B}$ ). To gain a further insight into the expression of ADR2B in melanoma cells, the influence of adrenergic stimulation on its cell surface expression was determined. There were no statistically significant differences in RFI values between the control and the AD-treated cells in all analysed cell lines. However, a significant difference in the percentage of ADR2B-positive cells after AD stimulation was observed in primary FM-55-P and 92-1 cells.

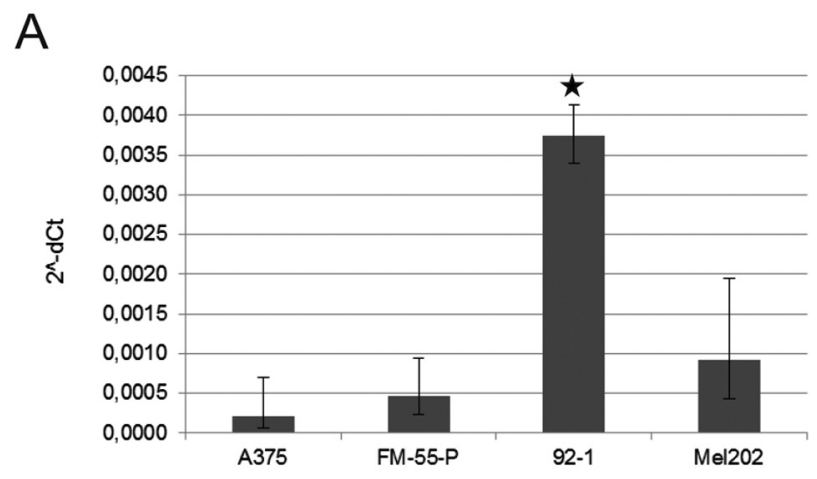

B

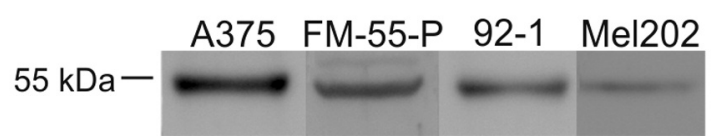

Figure 1. Expression of $A D R 2 B$ at the $m R N A$ and protein level in melanoma cell lines (CM and UM). (A) The expression level of target ADR2B mRNA was normalized to GAPDH and given as 2- $\triangle C t$. Results are means of three independent assays. Bars represent means $\pm S D$. Statistically significant differences are asterisked (Student's t-test, $p<0.05)$. (B) Target protein was detected with the use of specific antibodies in western blotting.

The effect of $A D$ treatment on matrix metalloproteinase activity. In view of Moretti et al.'s (17) observations concerning the altered expression of active forms of MMP2 and MMP-9 in melanoma cell lines cultured in the presence of catecholamines, gel zymography to examine matrix metalloproteinases was conducted (Figure 3). In all analysed cells, MMP-2 activity was detected. Moreover, the activity of pro-MMP-9 was reported only in primary melanoma cell lines and the intensity of the corresponding band was the most pronounced in 92-1 cells. In A375 cells, this form was not detected. A diverse MMP-2 activation after AD treatment was observed in A375, 92-1 and Me1202 cell lines but not in FM-55-P cells. The highest AD dose $(100 \mu \mathrm{M})$ caused significant MMP-2 activation relative to control. The other applied doses had no effect or slightly decreased the level of the active MMP-2 form in A375 cells. In Mel202 cells, AD stimulation mostly increased the level of activated MMP-2. In 92-1 cells, there was an opposite effect: significantly decreased levels of the active form of MMP-2 were detected in case of AD treatment, regardless of the dosage used. FM-55-P cells showed no statistically significant differences in MMP-2 activation between control and AD-stimulated cells (Figure 3). In AD-stimulated primary melanoma cells, all doses administered caused a weak MMP-9 expression, while, in A375 cells, only $100 \mu \mathrm{M}$ of $\mathrm{AD}$ resulted in induction of this MMP form. Additionally, 
a band of $130 \mathrm{kDa}$ was visualized only in both CM cell lines. This band may be attributable to the MMP-9/tissue inhibitor of metalloproteinases-1 (TIMP-1) complex, previously described (24); however, this hypothesis needs further verification. Its marked presence in samples originated from A375 cells may provide an explanation of the weak intensity of the bands representing pro-MMP-9 protein in this cell line.

$A D$ stimulation affects the proliferation and migration properties of CM and UM cells in various ways. The evidence relating the role of stress in cancer progression is contradictory. Both increased and decreased rates of cancer cell proliferation, migration, invasion and tumour growth after catecholamine stimulation have been reported (25). Such observation has been made for various types of cancer, including breast (26), pancreatic (27) and others. To better understand the functional role of AD stimulation in melanoma cells, we measured proliferation (Figure 4) and migration rates (Figure 5). It was shown that primary melanoma cells were more susceptible to AD treatment; they responded mostly by lowering their proliferation rate. In the case of Mel202 cells, their proliferation rate was lower after application of 1 or $10 \mu \mathrm{M}$ of $\mathrm{AD}$, whereas 92-1 cells showed a slight decrease in proliferation after treatment with $0.1,1$ and $10 \mu \mathrm{M}$ AD. The most pronounced effect was observed in FM-55-P cell line: all applied AD doses resulted in decreased cell proliferation. On the contrary, A375 cells responded by increasing their proliferation rate only, however, at the highest applied AD dose $(100 \mu \mathrm{M})$ (Figure 4$)$.

Subsequently, we investigated the effect of $\mathrm{AD}$ on melanoma cell migration as estimated in assays of wound healing on a plastic or FN-coated surface (Figure 5A-C). Previously reported wound-healing experiments in the herein analysed melanoma cell lines have revealed that the extent of wound closure on FN was over $70 \%$ for A375 (28), about $18 \%$ for FM-55-P cells and about $36 \%$ for both UM cell lines (29). First, we determined the role of AD in A375 cells migration rate on FN. Our results revealed that A375 cells migrated slower on FN after administration of all AD doses employed, while, on plastic, there was a difference observed only in the case of $10 \mu \mathrm{M}$ of AD (Figure 5A). Then, based on our observation that $10 \mu \mathrm{M}$ of $\mathrm{AD}$ was the only dose that decreased the proliferation to comparable level in all analysed primary melanoma cell lines, we tested the migration rate of melanoma cells on $\mathrm{FN}$ at this specific concentration (Figure 5B). Obtained results showed that FM55-P cells migrated faster when seeded on the FN-coated surface, as it was expected, independently of AD treatment. The response of UM cells was consistent as both 92-1 and Mel202 cells markedly increased their migration speed after AD treatment.
A

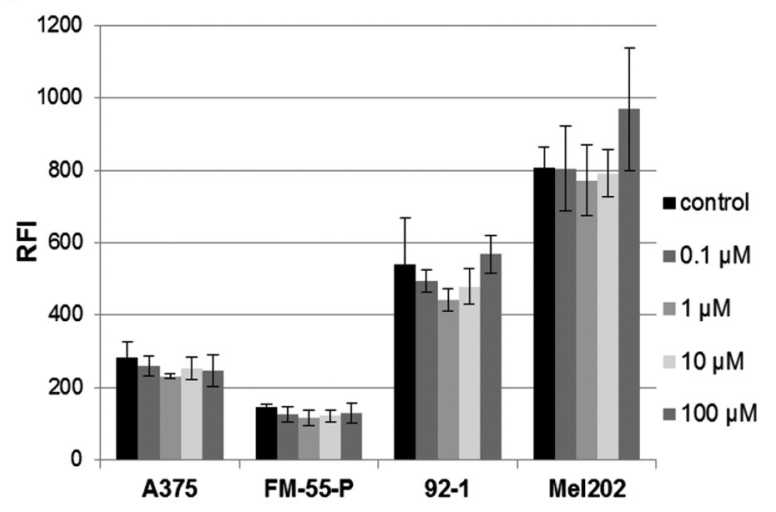

B

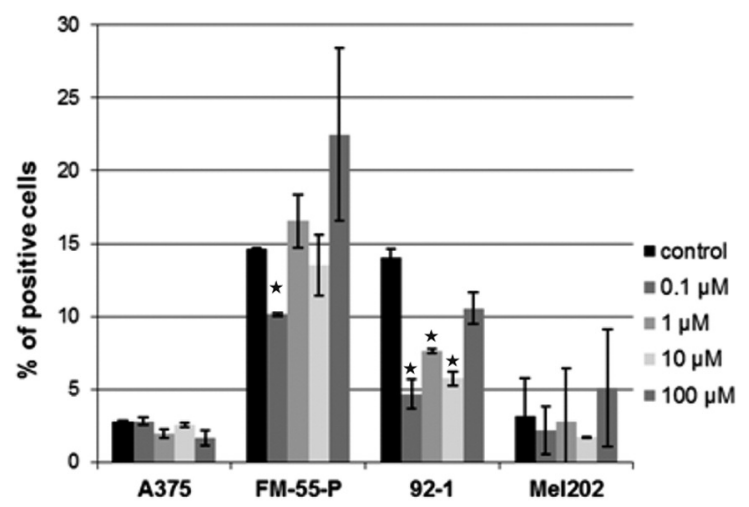

Figure 2. Adrenaline does not change the ADR2B expression in melanoma cells. (A) Quantification of relative fluorescent intensity (RFI) from flow cytometry analyses in control and adrenaline-stimulated $C M$ and UM melanoma cells. (B) Percentage of ADR2B-positive cells in control and $A D$-treated cells. Values are expressed as means $\pm S D$ of three separate experiments. Statistically significant differences are asterisked (Duncan's test, $p<0.05$ ).

\section{Discussion}

During the last several years, efforts to include psychological stress among risk factors generally accepted to be conducive to melanoma progression have been observed. Clinical findings that $\beta$-blockers might inhibit cancer progression (12, $14,15,30,31)$ have sparked hopes for more effective cancer treatment. These studies have also inspired numerous in vivo and in vitro studies focused on elucidation of the mechanisms of catecholamines' action in cancer. As various cancers, including melanoma, are concerned, a positive correlation between the level of stress in cancer patients and progression of disease has been demonstrated $(8,32)$. However, attempts to explain the molecular mechanisms of $\mathrm{AD}$ action in cancer progression (33-35) have still not brought clear conclusion(s) despite thorough investigation. 

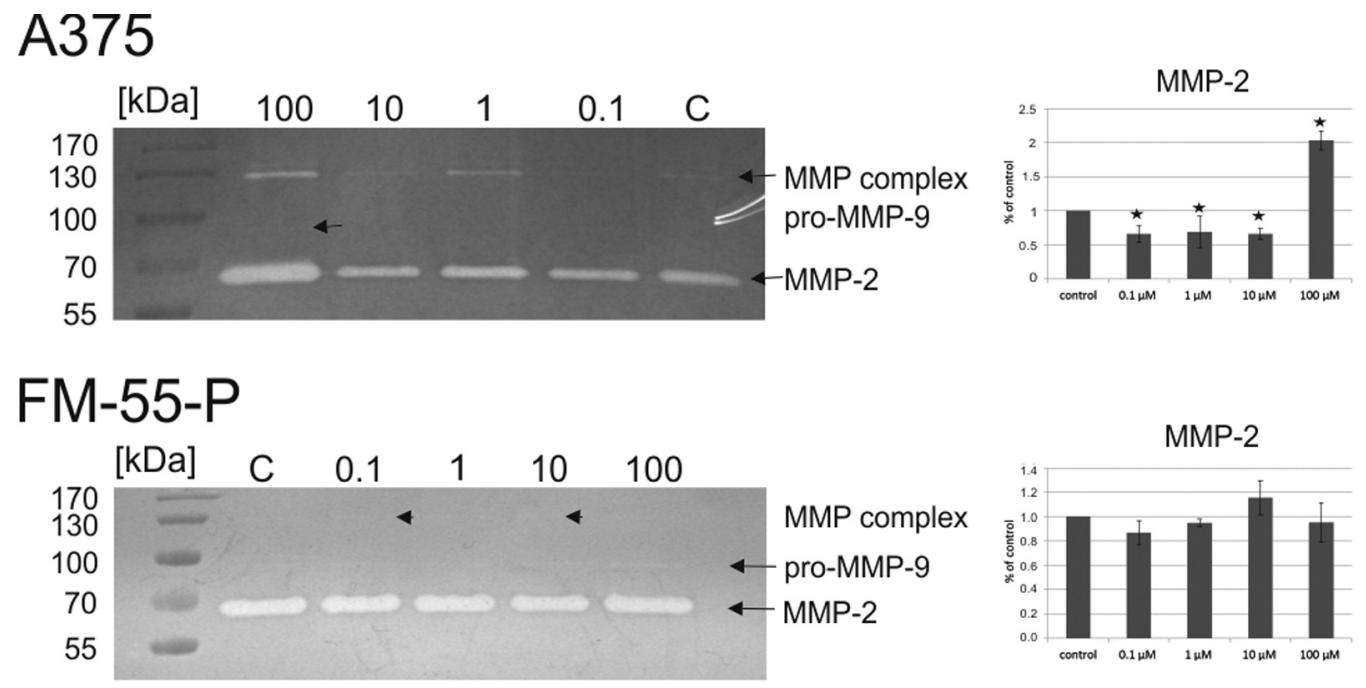

\section{2-1}
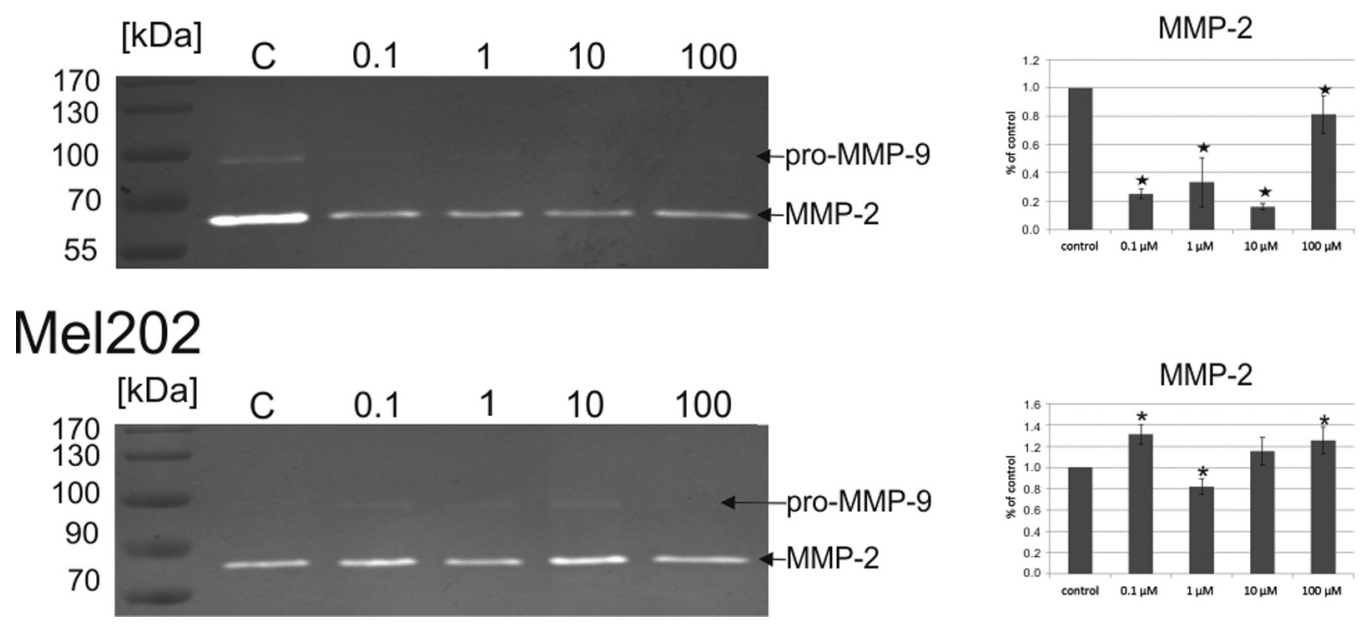

Figure 3. Abundant activation of metalloproteinase (MMP)-2 in melanoma cell lines. MMPs' activation was determined by zymography in CM and UM cells treated with adrenaline in selected doses. Semi-quantitative analysis of MMP-2 band intensity was performed with the use of UVImap software. Values are expressed as means \pm standard deviation of three independent experiments. Statistically significant differences are asterisked (Duncan's test, $p<0.05$ ).

The adrenergic stimulation is suggested to accelerate cancer progression via stimulation of angiogenesis (36), regulation of MMP expression and activation (37), as well as by increased tumour cell proliferation (26). In melanoma tissues and cell lines, the expression of ADR2B has been previously reported $(17,38,39)$. In the study of Yang et al. (38), the expression of ADR2B has been confirmed in the majority of analyzed melanoma tissue biopsies. Additionally, analysis of melanoma tissue samples performed by Moretti et al. (17) has shown higher ADR2B expression level in malignant biopsies. Further insight into ADR2B expression in melanoma biopsies have suggested its prognostic value in course of melanoma and demonstrated positive correlation between elevated ADR2B expression in patients' tissue samples and poor survival rate (39). Additionally, it has been shown that metastatic melanoma A375 cells from primary tumour exhibited higher expression of ADR2B, both at mRNA and protein level than malignant melanoma Hs-29-4T cells from secondary tumour (17). Our present results revealed that melanoma cells, despite their origin and malignancy, exhibited both $A D R 2 B$ mRNA expression and corresponding protein. Our observations were consistent with a previous study by Moretti et al. (17) showing that $A D R 2 B$ expression in melanoma cells decreases in relation to growing metastatic potential of tumour cells. 
Moreover, our results are consistent with the observation concerning $A D R 2 B$ expression in breast cancer cells. Gargiulo et al. (26) have shown that the non-tumourigenic MCF-10A cells possess generally higher level of ADRB than tumour MCF-7 cells. Regarding their previously published results, they have suggested that this observation refers mainly to ADR2B. These authors have also reported that, in nontumourigenic cells, AD treatment resulted in decreased proliferation and migration rate and higher cellular adhesion, whereas, in tumour cells, the effect was opposite, i.e. AD stimulation accelerated proliferation and migration of cancer cells (26). Our results showed, for the first time, that primary melanoma cell proliferation rate is lower after AD stimulation. Additionally, AD treatment caused an increase in proliferation of metastatic melanoma A375 cells; however, this effect was observed only in the case of the highest AD dose. Our observations were in line with the results previously reported by Yang et al. (38) who have shown noradrenaline-dependent (acting via ADRB) increase in proliferation rate of metastatic melanoma cells. Increase in proliferation after AD treatment has been also reported in metastatic colon cancer and adenocarcinoma HT-29 cells (40).

Our results suggested that there were no detectable patterns of melanoma cell response to $\mathrm{AD}$ that could distinguish CM from UM cells or primary from metastatic melanoma cells. The only difference between CM and UM cells was observed in the zymography assay. In both CM cell lines, unlike UM cells, a band of $130 \mathrm{kDa}$ corresponding to MMP complexes was detected. Moretti et al. (17) have shown that catecholamines (AD and noradrenaline) enhance the motility and invasiveness of melanoma A375 and Hs29$4 \mathrm{~T}$ cells. These authors have also reported more abundant activation of MMP-2 and MMP-9, which suggested that catecholamines promote the metastatic behaviour of melanoma cells. Our observations partially confirmed that hypothesis, showing stronger activation of MMP-2 than MMP-9 in both CM and UM melanoma cells. It is commonly accepted that the presence and activity of MMPs promote the ability of cancer cells to migrate through the surrounding tissue and cross the basal membrane barrier (36). Moretti et al. (17) reported higher Matrigel invasion rate after AD stimulation of melanoma cells. This was not confirmed by our results from the wound-healing assay. There was not an explicit effect of $\mathrm{AD}$ on $\mathrm{CM}$ cells migration; however, UM cells seemed to be more susceptible to $\mathrm{AD}$ treatment. In both $\mathrm{UM}$ cell lines, $\mathrm{AD}$ stimulation caused a significantly faster migration of these cells. Simultaneously, we observed a higher migration rate on FN versus plastic, which was consistent with our previously published results regarding migration of melanoma cells (28, 29) and the expression level of integrin $\alpha 5 \beta 1(29,41)$, which is a classical FN receptor. The already described differences in integrin $\alpha 5 \beta 1$ expression level between CM and UM cells

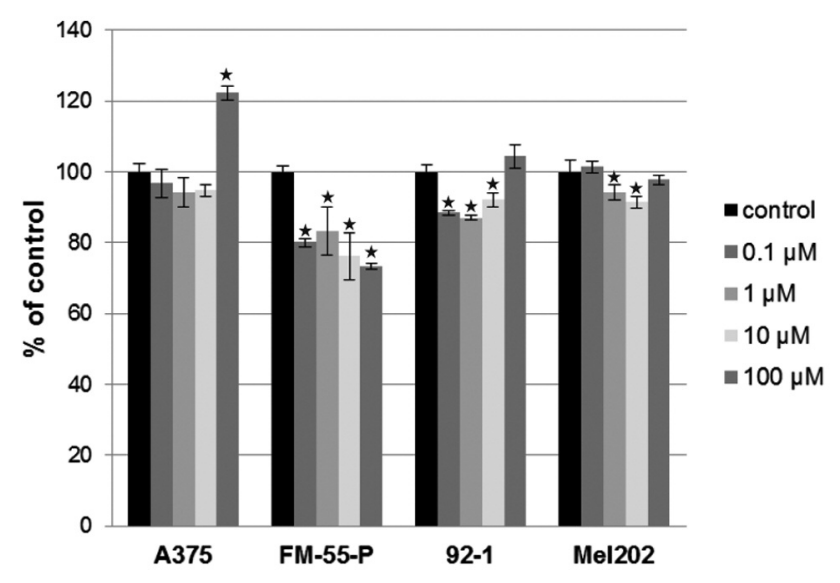

Figure 4. Adrenaline decreases proliferation in primary melanoma cells and does not modify proliferation in A375 cells. Alamar Blue assay was used to test the proliferation of adrenaline-treated melanoma cells. Results are presented relative to control (cells without additions, taken as $100 \%)$. Three independent experiments were conducted. Statistically significant differences are asterisked (Duncan's test, $p<0.05$ ).

may provide an explanation for the observed differences in their migration on FN. Slower migration on FN than plastic observed in 92-1 cells may be attributed to already reported low integrin $\alpha 5 \beta 1$ expression level.

On the other hand, interesting observations have been made in breast cancer cells that have enabled to identify the dual mechanism of ADR2B activation (42). It has been demonstrated that low concentration of agonist (isoproterenol) increases adhesion of breast cancer cells, whereas higher doses lead to decreased proliferation of these cells. The different activation of signalling pathways has been suggested in this model as an explanation for the observed phenomenon. The authors have suggested that the agonist in low concentration binds preferentially to ADR2B population localised in raft microdomains, therefore activating a dedicated Gs/cAMP/EPAC signalling pathway, which, finally, leads to adhesion. In case of high dose of agonist, activation of receptor population localized outside the rafts and Gs/cAMP/PKA signalling pathways activation has been observed (42). These dualistic mechanisms of adrenergic receptor action may serve as an additional explanation for our inconsistent observations regarding melanoma cell migration and proliferation after AD treatment. This hypothesis, however, needs further investigation.

Taken together, our results demonstrated that, in case of UM cells, their response to AD treatment was coherent and both cell lines showed higher migration rate in the presence of AD. It is of note that there was no effect on UM cell proliferation. These observations might be related to the higher ADR2B expression level in UM cells in comparison to $\mathrm{CM}$ 
A

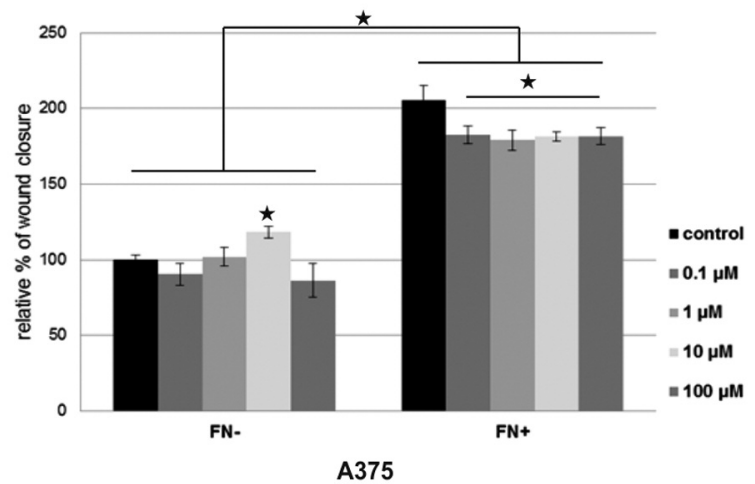

C
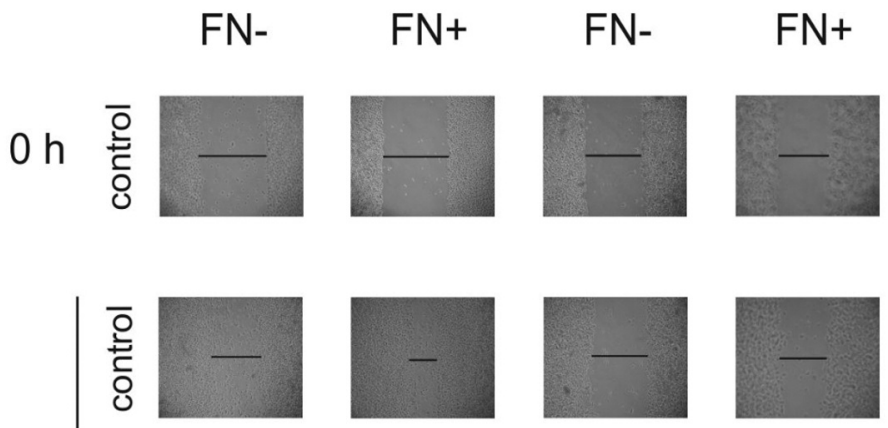

$24 \mathrm{~h}$

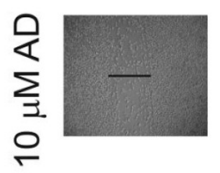

B
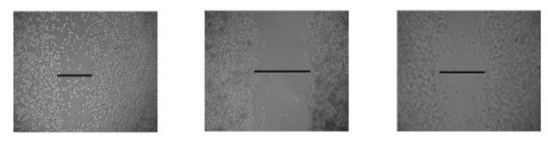

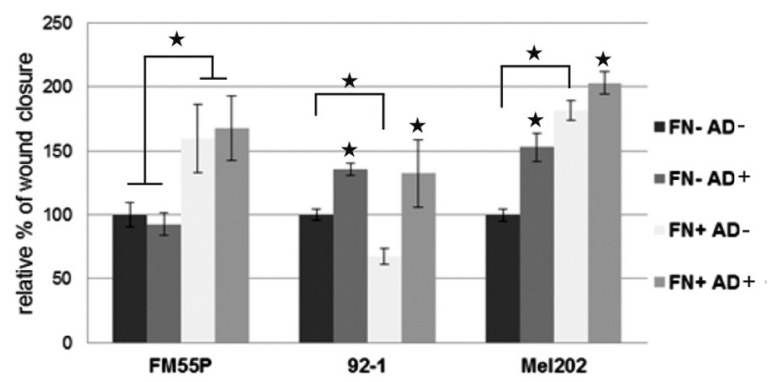

92-1

Mel202

FN-

$\mathrm{FN}+$

FN-

$\mathrm{FN}+$
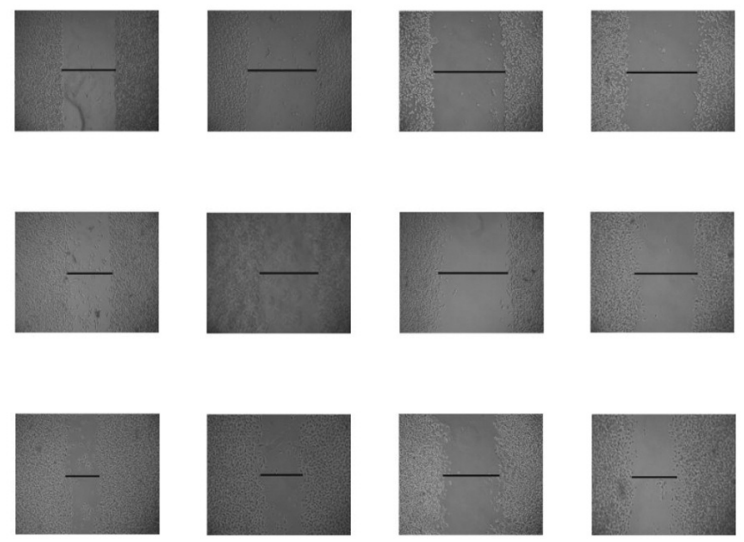

Figure 5. UM but not CM cells respond to adrenaline (AD) stimulation by increasing their migration rate. The repair of wounds in monolayers of human cutaneous A375 and FM-55-P, as well as uveal 92-1 and Mel202 melanoma cells, was tested on plastic and fibronectin (FN)-coated surfaces. Wounds were scratched with a plastic pipette tip through a confluent monolayer and cultures were allowed to heal for $24 \mathrm{~h}$ in the presence of the selected doses of $A D$. (A) Effect of $A D$ treatment on repair of scratch wounds in monolayers of $A 375$ cells cultured on plastic and FN-coated surfaces. (B) Effect of $A D(10 \mu M)$ on repair of scratch wounds in monolayers of FM-55-P, 92-1 and Mel202 cells cultured on plastic and FN-coated surfaces. (C) Photos of cells migrated into wound area in the presence of $A D(10 \mu M)$ on plastic or FN-coated surfaces after 24 h. In both $(A)$ and $(B)$ panels, the extent of wound closure was assessed by measuring the wound width at the starting point $(0 h)$ and after 24 h. Changes in migration rate after adrenaline treatment are given as percentages of the migration of untreated cells. Values are means $\pm S D$ of three separate experiments. Statistically significant differences are asterisked (Duncan's test, $p<0.05$ ).

cells. In case of $\mathrm{CM}$ cells, we showed that $\mathrm{AD}$ did not stimulate but rather inhibited A375 cell migration on FN contradicting the findings of Moretti et al. (17) showing accelerated invasion after AD stimulation of A375 cells. In addition, the primary CM FM-55-P cells did not show any changes in migration rate in the presence of $10 \mu \mathrm{M}$ AD. These results are in line with the observed low $A D R 2 B$ mRNA and ADR2B expression levels in FM-55-P cells, as well as lack of changes in their MMPs' activity after AD stimulation.
Investigation on ADR2B expression and migration of malignant melanoma A375 cells on FN showed more consistent response to $\mathrm{AD}$ treatment than those for the primary melanomas that might lead to the final conclusion that origin and/or higher tumourigenic capacity of A375 cells render them less sensitive to $\mathrm{AD}$ stimulation. However, it remains unclear whether these differences are the effect of the different origin of UM and CM cells or, rather, cell line-dependent. To our knowledge, this is the first-ever analysis of the effect of $\mathrm{AD}$ 
on UM cells. For a true understanding of the role of adrenergic stimulation in melanoma progression, more detailed analyses of the response of CM and UM cells, both primary and metastatic, to $\mathrm{AD}$ and noradrenaline are required.

\section{Acknowledgements}

This work was supported by the grant no. K/ZDS/006309 from the Jagiellonian University in Krakow, Poland.

\section{References}

1 Mohr P, Eggermont AMM, Hauschild A and Buzaid A: Staging of cutaneous melanoma. Ann Oncol 20(Suppl 6): vi14-vi21, 2009.

2 MacKie RM, Hauschild A and Eggermont AM: Epidemiology of invasive cutaneous melanoma. Ann Oncol 20(Suppl 6): vi1-vi7, 2009.

3 Ragan AR, Leśniak A, Bochynska-Czyż M, Kosson A, Szymańska H, Pysniak K, Gajewska M, Lipkowski AW and Sacharczuk M: Chronic mild stress facilitates melanoma tumor growth in mouse lines selected for high and low stress-induced analgesia. Stress 16(5): 571-580, 2013.

4 Colucci R and Moretti S: The role of stress and beta-adrenergic system in melanoma: Current knowledge and possible therapeutic options. J Cancer Res Clin Oncol 142(5): 1021-1029, 2016.

5 Eng JW, Kokolus KM, Reed CB, Hylander BL, Ma WW and Repasky EA: A nervous tumor microenvironment: the impact of adrenergic stress on cancer cells, immunosuppression, and immunotherapeutic response. Cancer Immunol Immunother 63(11): 1115-1128, 2014.

6 Repasky EA, Eng J and Hylander BL: Stress, metabolism and cancer: Integrated pathways contributing to immune suppression. Cancer J 21(2): 97-103, 2015.

7 Sinnya S and De'ambrosis B: Stress and melanoma: increasing the evidence towards a causal basis. Arch Dermatol Res 305(9): 851-856, 2013.

8 Armaiz-Pena GN, Cole SW, Lutgendorf SK and Sood AK: Neuroendocrine influences on cancer progression. Brain Behav Immun 30(Suppl): S19-25, 2013.

9 Valles SL, Benlloch M, Rodriguez ML, Mena S, Pellicer JA, Asensi M, Obrador E and Estrela JM: Stress hormones promote growth of B16-F10 melanoma metastases: An interleukin 6- and glutathione-dependent mechanism. J Transl Med 11: 72, 2013.

10 Hanahan D and Weinberg RA: Hallmarks of cancer: The next generation. Cell 144(5): 646-674, 2011.

11 Tang J, Li Z, Lu L and Cho CH: $\beta$-Adrenergic system, a backstage manipulator regulating tumour progression and drug target in cancer therapy. Semin Cancer Biol 23(6 Pt B): 533-542, 2013.

12 Stiles JM, Amaya C, Rains S, Diaz D, Pham R, Battiste J, Modiano JF, Kokta V, Boucheron LE, Mitchell DC and Bryan BA: Targeting of beta adrenergic receptors results in therapeutic efficacy against models of hemangioendothelioma and angiosarcoma. PLoS One 8(3): e60021, 2013.

13 Liao X, Che X, Zhao W, Zhang D, Bi T and Wang G: The $\beta$ adrenoceptor antagonist, propranolol, induces human gastric cancer cell apoptosis and cell cycle arrest via inhibiting nuclear factor $\mathrm{kB}$ signaling. Oncol Rep 24(6): 1669-1676, 2010.
14 Montoya A, Amaya CN, Belmont A, Diab N, Trevino R, Villanueva G, Rains S, Sanchez LA, Badri N, Otoukesh S, Khammanivong A, Liss D, Baca ST, Aguilera RJ, Dickerson EB, Torabi A, Dwivedi AK, Abbas A, Chambers K, Bryan BA and Nahleh Z: Use of non-selective $\beta$-blockers is associated with decreased tumor proliferative indices in early stage breast cancer. Oncotarget 8(4): 6446-6460, 2017.

15 Pasquier E, Street J, Pouchy C, Carre M, Gifford AJ, Murray J, Norris MD, Trahair T, Andre N and Kavallaris M: $\beta$-blockers increase response to chemotherapy via direct antitumour and anti-angiogenic mechanisms in neuroblastoma. Br J Cancer 108(12): 2485-2494, 2013.

16 Maccari S, Buoncervello M, Rampin A, Spada M, Macchia D, Giordani L, Stati T, Bearzi C, Catalano L, Rizzi R, Gabriele L and Marano G: Biphasic effects of propranolol on tumour growth in B16F10 melanoma-bearing mice. Br J Pharmacol 174(2): 139-149, 2017.

17 Moretti S, Massi D, Farini V, Baroni G, Parri M, Innocenti S, Cecchi $\mathrm{R}$ and Chiarugi $\mathrm{P}$ : $\beta$-adrenoceptors are upregulated in human melanoma and their activation releases pro-tumorigenic cytokines and metalloproteases in melanoma cell lines. Lab Invest 93(3): 279-290, 2013.

18 Powe DG, Voss MJ, Habashy HO, Zanker KS, Green AR, Ellis IO and Entschladen F: Alpha- and beta-adrenergic receptor (AR) protein expression is associated with poor clinical outcome in breast cancer: An immunohistochemical study. Breast Cancer Res Treat 130: 457-463, 2011.

19 Dal Monte M, Casini G, Filippi L, Nicchia GP, Svelto M and Bagnoli P: Functional involvement of $\beta 3$-adrenergic receptors in melanoma growth and vascularization. J Mol Med (Berl) 91(12): 1407-1419, 2013.

20 Weitl N and Seifert R: Distinct interactions of human beta1- and beta2-adrenoceptors with isoproterenol, epinephrine, norepinephrine, and dopamine. J Pharmacol Exp Ther 327(3): 760-769, 2008.

21 Krizanova O, Babula P and Pacak K: Stress, catecholaminergic system and cancer. Stress 19(4): 419-428, 2016.

22 Peterson GL: A simplification of the protein assay method of Lowry et al. which is more generally applicable. Anal Biochem 83(2): 346-356, 1977.

23 Laemmli UK: Cleavage of structural proteins during the assembly of the head of bacteriophage T4. Nature 227: 690-685, 1970.

24 Hahn-Dantona E, Ruiz JF, Bornstein P and Strickland DK: The low density lipoprotein receptor-related protein modulates levels of matrix metalloproteinase 9 (MMP-9) by mediating its cellular catabolism. J Biol Chem 276(18): 15498-15503, 2001.

25 Coelho M, Soares-Silva C, Brandão D, Marino F, Cosentino M and Ribeiro L: $\beta$-Adrenergic modulation of cancer cell proliferation: Available evidence and clinical perspectives. J Cancer Res Clin Oncol 143(2): 275-291, 2017.

26 Gargiulo L, Copsel S, Rivero EM, Galés C, Sénard JM, Lüthy IA, Davio C and Bruzzone A: Differential $\beta_{2}$-adrenergic receptor expression defines the phenotype of non-tumorigenic and malignant human breast cell lines. Oncotarget 5(20): 1005810069, 2014.

27 Kim-Fuchs C, Le CP, Pimentel MA, Shackleford D, Ferrari D, Angst E, Hollande F and Sloan EK: Chronic stress accelerates pancreatic cancer growth and invasion: A critical role for betaadrenergic signaling in the pancreatic microenvironment. Brain Behav Immun 40: 40-47, 2014. 
28 Lityńska A, Przybyło M, Pocheć E, Kremser E, Hoja-Łukowicz $\mathrm{D}$ and Sulowska U: Does glycosylation of melanoma cells influence their interactions with fibronectin? Biochimie 88(5): 527-534, 2006.

29 Przybyło M, Pocheć E, Link-Lenczowski P and Lityńska A: Beta1-6 branching of cell surface glycoproteins may contribute to uveal melanoma progression by up-regulating cell motility. Mol Vis 14: 625-636, 2008.

30 Engineer DR, Burney BO, Hayes TG and Garcia JM: Exposure to ACEI/ARB and $\beta$-blockers is associated with improved survival and decreased tumor progression and hospitalizations in patients with advanced colon cancer. Transl Oncol 6(5): 539$545,2013$.

31 Lemeshow S, Srrensen HT, Phillips G, Yang EV, Antonsen S, Riis AH, Lesinski GB, Jackson R and Glaser R: $\beta$-blockers and survival among Danish patients with malignant melanoma: A population-based cohort study. Cancer Epidemiol Biomarkers Prev 20(10): 2273-2279, 2011.

32 Kasparian NA: Psychological care for people with melanoma: What, when, why and how? Semin Oncol Nurs 29(3): 214-222, 2013.

33 Obeid EI and Conzen SD: The role of adrenergic signaling in breast cancer biology. Cancer Biomark 13(3): 161-169, 2013.

34 Sun X, Bao J, Nelson KC, Li KC, Kulik G and Zhou X: Systems modeling of anti-apoptotic pathways in prostate cancer: Psychological stress triggers a synergism pattern switch in drug combination therapy. PLoS Comput Biol 9(12): e1003358, 2013.

35 Yang EV and Eubank TD: The impact of adrenergic signaling in skin cancer progression: Possible repurposing of $\beta$-blockers for treatment of skin cancer. Cancer Biomark 13(3): 155-160, 2013.

36 Chakroborty D, Sarkar C, Basu B, Dasgupta PS and Basu S: Catecholamines regulate tumor angiogenesis. Cancer Res 69(9): 3727-3730, 2009
37 Sood AK, Bhatty R, Kamat AA, Landen CN, Han L, Thaker PH, Li Y, Gershenson DM, Lutgendorf S and Cole SW: Stress hormone-mediated invasion of ovarian cancer cells. Clin Cancer Res 12(2): 369-375, 2006.

38 Yang EV, Kim S, Donovan EL, Chen M, Gross AC, Webster Marketon JI, Barsky SH and Glaser R: Norepinephrine upregulates VEGF, IL-8, and IL-6 expression in human melanoma tumor cell lines: Implications for stress-related enhancement of tumor progression. Brain Behav Immun 23: 267-275, 2009.

39 Shimizu A, Kaira K, Mori K, Kato M, Shimizu K, Yasuda M, Takahashi A, Oyama T, Asao T and Ishikawa O: Prognostic significance of $\beta 2$-adrenergic receptor expression in malignant melanoma. Tumour Biol 37(5): 5971-5978, 2016.

$40 \mathrm{Pu}$ J, Bai D, Yang X, Lu X, Xu L and Lu J: Adrenaline promotes cell proliferation and increases chemoresistance in colon cancer HT29 cells through induction of miR-155. Biochem Biophys Res Commun 428(2): 210-215, 2012.

41 Laidler P, Gil D, Pituch-Noworolska A, Ciołczyk D, Książek D, Przybyło M and Lityńska A: Expression of beta1-integrins and $\mathrm{N}$-cadherin in bladder cancer and melanoma cell lines. Acta Biochim Pol 47(4): 1159-1170, 2000.

42 Bruzzone A, Saulière A, Finana F, Sénard JM, Lüthy I and Galés $\mathrm{C}$ : Dosage-dependent regulation of cell proliferation and adhesion through dual $\beta 2$-adrenergic receptor/cAMP signals. FASEB J 28(3): 1342-1354, 2014.
Received April 14, 2017

Revised April 30, 2017

Accepted May 2, 2017 